\title{
Prediction on Permeability of Engineered Cementitious Composites
}

\author{
Qiannan Wang ${ }^{1}$, Guoshuai Zhang ${ }^{1}$, Yunyun Tong ${ }^{1, *}$ and Chunping Gu ${ }^{2,3}{ }^{\mathbb{D}}$ \\ 1 School of Civil Engineering and Architecture, Zhejiang University of Science and Technology, \\ Hangzhou 310023, China; wangqiannan@zust.edu.cn (Q.W.); 212002814023@zust.edu.cn (G.Z.) \\ 2 College of Civil Engineering, Zhejiang University of Technology, Hangzhou 310023, China; \\ guchunping@zjut.edu.cn \\ 3 Zhejiang Construction Investment Group, Hangzhou 310013, China \\ * Correspondence: 112013@zust.edu.cn
}

check for updates

Citation: Wang, Q.; Zhang, G.; Tong, Y.; Gu, C. Prediction on Permeability of Engineered Cementitious Composites. Crystals 2021, 11, 526. https://doi.org/10.3390/cryst11050526

Academic Editors: Nima Farzadnia, Yang Yu, Weiqiang Wang, Rafael Shehu and Beatrice Pomaro

Received: 8 April 2021

Accepted: 29 April 2021

Published: 10 May 2021

Publisher's Note: MDPI stays neutral with regard to jurisdictional claims in published maps and institutional affiliations.

Copyright: (c) 2021 by the authors. Licensee MDPI, Basel, Switzerland. This article is an open access article distributed under the terms and conditions of the Creative Commons Attribution (CC BY) license (https:// creativecommons.org/licenses/by/ $4.0 /)$.

\begin{abstract}
Permeability of concrete is regarded as a basic indicator of its durability. This paper proposed a simple model to predict the permeability of engineered cementitious composites (ECC), which are fiber reinforced cementitious composites with extremely high ductility and toughness. The permeability of cement paste in ECC was firstly determined based on the general effective media theory. The needed microstructure information of cement paste was obtained from a simulated microstructure. Porosity of the interfacial transition zone (ITZ) was obtained with an ITZ porosity model, and then used to calculate the permeability of ITZ. The permeability of the matrix was determined according to the general self-consistent scheme, and the influence of fiber was simplified with its volume fraction. The calculated permeability of ECC was verified with results from water permeability tests and the accuracy of the model was acceptable for cement-based materials.
\end{abstract}

Keywords: engineered cementitious composites; permeability; model; porosity; paste

\section{Introduction}

Concrete is a brittle material and cracks easily. The micro- and macro-cracks create easy access routes for deleterious agents, resulting in greatly compromised durability of concrete structures [1]. The concerns with the inferior fracture toughness of concrete are alleviated to a large extent by reinforcing it with fibers, resulting in fiber reinforced concrete (FRC). During the last two decades, a significant effort has been made on developing and researching a new class of FRC, the so-called engineered cementitious composites (ECC). ECC exhibit strain-hardening behavior and high strain capacity in tension, while maintaining very tight crack widths (typically below $100 \mu \mathrm{m}$ ) [2]. These unique behaviors of ECC result from an elaborate design using a micro-mechanical model taking into account the interactions among fiber, matrix and the fiber-matrix interface [3]. The unique features of ECC make it a perfect material for repair purposes.

Permeability of concrete is one of the most important characteristics for durability [4]. Being the first line of attack against deleterious agents, it is important that the permeability of repair material be investigated. Some experimental work [5-9] has been carried out to study the permeability of ECC, while there is no existing model proposed to predict it yet.

Most of the present permeability models are based on the microstructure and are mainly aimed for cement paste [10]. Christensen et al. [11] used the Katz and Thompson permeability theory to calculate the permeability of cement paste with high capillary porosity; the result was in good agreement with the experiment. However, for low porosity cement paste, where permeation occurs in both capillary and gel pores, the Katz and Thompson permeability theory is not applicable [12]. Koster [13] and Park [14] adopted Hagen-Poiseuille's law to determine the flow rate in a representative elementary volume of cement paste, and then calculated permeability with Darcy's law. They found the results were in good agreement 
with experiment results. Cui and Cahyadi [15] proposed a model to calculate permeability of cement paste based on general effective media (GEM) theory and got close results with experiments. To obtain permeability of concrete from that of paste, multi-scale modeling methods are often adopted $[16,17]$. However, the calculations of these models are usually complicated, and some of them require specialized software. Hashin [18] proposed a composite spheres assemblage (CSA) model, which could be used to calculate the conduction of concrete. However, the CSA model is derived based on the assumption that the thickness of the interfacial transition zone (ITZ) is proportional to the radius of aggregate particle. This is not realistic, and it seems rather practical to assume that the ITZ thickness is same for all particles as Garboczi and Bentz [19] did. Based on the above considerations, Oh and Jang [20] proposed a general self-consistent scheme (GSCS) to predict the diffusivity of concrete and obtained good agreement with experimental results.

This paper proposed a simple model for calculating permeability of ECC. The permeability of cement paste was firstly determined with GEM theory, and then used to calculate the permeability of ECC based on the GSCS method, where most parameters were obtained easily with the raw materials information. In addition, water permeability tests were performed to verify the reliability of the proposed model.

\section{Theoretical Analysis}

\subsection{Darcy's Law}

The permeation process in cement-based materials under steady state can be described with Darcy's law [21],

$$
q=-\frac{\kappa}{\eta} \nabla P
$$

where $q$ is the rate of fluid flow $(\mathrm{m} / \mathrm{s}), \eta$ is dynamic viscosity of the fluid (Pa.s) and $P$ is the pressure (Pa). $\kappa$ is permeability of cement-based material $\left(\mathrm{m}^{2}\right)$, which is dependent purely on the characteristics of the material and independent on the fluid properties. For permeation of water in cement-based materials, the intrinsic permeability $\kappa$ can be converted into saturated water permeability $K_{w}(\mathrm{~m} / \mathrm{s})$ with

$$
K_{W}=\kappa \frac{\rho_{W} g}{\eta}
$$

where $\rho_{W}$ and $g$ represent the water density $\left(\mathrm{kg} / \mathrm{m}^{3}\right)$ and acceleration of gravity $\left(\mathrm{m} / \mathrm{s}^{2}\right)$, respectively.

\subsection{Permeability of ECC Cement Paste}

According to the GEM theory [15], the cement paste can be regarded as a two-phase composite material. One of the phases is the capillary pores with high permeability. The other one is the low-permeability phase that consists of C-S-H gel, $\mathrm{CH}$ and unhydrated particles. The permeability of cement paste $\kappa_{p}$ can be calculated with

$$
\begin{aligned}
& \frac{(1-\varphi)\left(\kappa_{l}^{1 / 2}-\kappa_{p}^{1 / 2}\right)}{\kappa_{l}^{1 / 2}+A \kappa_{p}^{1 / 2}}+\frac{\varphi\left(\kappa_{h}^{1 / 2}-\kappa_{p}^{1 / 2}\right)}{\kappa_{h}^{1 / 2}+A \kappa_{p}^{1 / 2}}=0 \\
& A=\frac{1-\varphi_{c}}{\varphi_{c}}
\end{aligned}
$$

where $\kappa_{h}$ is the permeability of high-permeability phase $\left(\mathrm{m}^{2}\right), \kappa_{l}$ is the permeability of low-permeability phase $\left(\mathrm{m}^{2}\right), \varphi$ is the capillary porosity and $\varphi_{c}$ is the critical capillary porosity $\left(\varphi_{c}=0.18[22]\right)$.

The permeability of high-permeability phase $\kappa_{h}$ can be calculated with the following equation:

$$
\kappa_{h}=\frac{1.8}{226} r_{\text {peak }}^{2}\left(1-\varphi_{c}\right)^{2}
$$


where $r_{\text {peak }}$ is the peak radius of the capillary pores (m). The permeability of low-permeability phase can be determined with

$$
\kappa_{l}=\kappa_{C-S-H}\left(1-\frac{1-V_{C-S-H}}{1-V_{c}^{\prime}}\right)^{2}
$$

where $\kappa_{\mathrm{C}-\mathrm{S}-\mathrm{H}}$ is the permeability of C-S-H gel, which is $7 \times 10^{-23} \mathrm{~m}^{2}$ according to Powers [23], $V_{C-S-H}$ is the volume fraction of C-S-H gel in the low-permeability phase and $V_{c}{ }^{\prime}$ is the critical volume fraction of C-S-H gel which is taken as 0.17 [24].

Some microstructure-related parameters need to be determined in order to calculate the permeability of cement paste with GEM theory. These parameters could be provided by some well-developed microstructure models for cement paste $[25,26]$. Among all these models, HYMOSTRUC [27], CEMHYD3D [28], $\mu$ ic [29] and DUCOM [30] are the relatively mature and generally accepted models. HYMOSTRUC model was proposed in the 1990s to simulate the hydration process and microstructure of cement paste. It is also applicable for simulating paste containing slag, fly ash and silica fume now. Details about HYMOSTRUC model can be found in [31,32]. The simulated microstructures were verified with experiments and showed good consistency [33]. The microstructure of ECC paste in this study was simulated with the HYMOSTRUC model, and then used to determine the permeability of ECC cement paste with GEM theory.

\subsection{Permeability of ECC}

Sand particles in mortar are usually considered as non-permeable phase and their permeability is normally taken as zero when modeling permeability of mortar. The presence of sand reduces the volume fraction of permeable phases in mortar, and that is the main reason why the permeability of mortar is usually lower than that of cement paste. The presence of sand also increases the tortuosity of water's transport path and consequently reduces the permeability. However, the ITZ between the cement bulk paste and the sand particles has much higher porosity and larger pore size than cement paste, which results in a higher permeability in mortar. In order to predict the permeability of an ECC matrix, the GSCS method was adopted to calculate the permeability of mortar matrix. The scheme was discussed extensively in the literature, and it has been proven to be a simple, yet realistic, method to be used for reasonable durability design of concrete structures [20,34]. According to the GSCS method, mortar can be regarded as a three-phase composite material composed of bulk cement paste, spherical sand particle and ITZ. By assuming the interface thickness is same for all sand particles and the permeability of sand particle is zero, the permeability of matrix mortar $\kappa_{m}$ can be calculated with

$$
\kappa_{m}=\kappa_{p}\left[1+\frac{V_{s}}{\frac{1}{2\left(\kappa_{i} / \kappa_{p}\right) \bar{\varepsilon}-1}+\frac{1-V_{s}}{3}}\right]
$$

where vs. is the volume fraction of sand, $\kappa_{i}$ is the permeability of ITZ $\left(\mathrm{m}^{2}\right)$ and $\bar{\varepsilon}$ is the ratio of the thickness of ITZ $\left(t_{i}\right)$ to the average radius of sand particles $\left(\overline{r_{s}}\right)$.

The thickness and porosity of ITZ can be influenced by various factors, such as the water to binder $(\mathrm{w} / \mathrm{b})$ ratio, aggregate features, curing age, etc. Zheng et al. [35] developed an algorithm to simulate the three-dimensional distribution of cement particles between aggregates in concrete. Based on his algorithm, Sun [36] proposed a porosity model of ITZ in concrete and calculated the averaged porosity of ITZ $\varphi_{i}$, as shown in Figure 1 . The results were fitted in this study to build a relationship between $\varphi_{i} / \varphi_{p}$ and $\varphi_{p}$ as follows:

$$
\varphi_{i} / \varphi_{p}=1.49+3.35 \times\left(1.34 \times 10^{-7}\right)^{\varphi_{p}}
$$




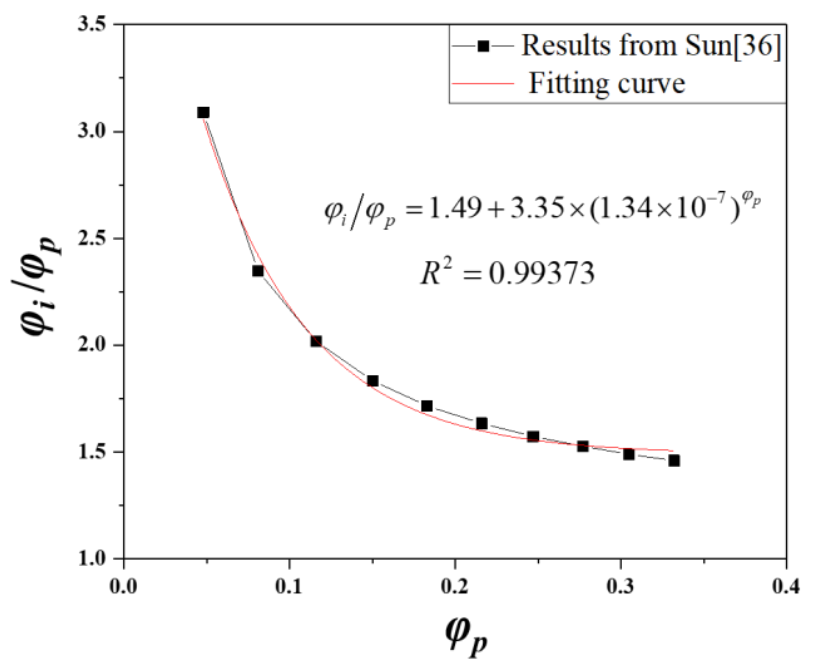

Figure 1. Fitted relationship between $\varphi_{i}$ and $\varphi_{p}$.

The averaged porosity of ITZ could be easily calculated using Equation (7) with known porosity of the bulk paste. The permeability of ITZ can then be calculated based on the Katz-Thompson theory [37], as shown in Equation (8).

$$
\kappa_{i}=\frac{0.18}{226} r_{i}^{2}\left(\varphi_{i}-\varphi_{c}\right)^{2}
$$

where $r_{i}$ is the peak radius of capillary pores in ITZ (m). The parameter $r_{i}$ is difficult to determine. For a couple of simulated $\varphi_{p}$ and $r_{p e a k}$, the relationship between $\varphi_{i} / \varphi_{p}$ is taken to calculate $r_{i}$ with $r_{\text {peak }}$. Sun [36] studied the porosity distribution of ITZ in concrete with $\mathrm{w} / \mathrm{b}$ ratios of $0.23,0.35$ and 0.53 , respectively. It was found that within the studied range of $\mathrm{w} / \mathrm{b}$ ratio, the porosity of ITZ became stable at $20 \mu \mathrm{m}$ from the aggregate surface and the porosity there was almost the same with porosity of bulk cement paste. That was to say, the thickness of ITZ was about $20 \mu \mathrm{m}$. Scrivener [38] pointed out that the thickness of ITZ was between 10-30 $\mu \mathrm{m}$ for ordinary concrete. In this study, the thickness of ITZ was taken as $20 \mu \mathrm{m}$.

Another parameter to be determined in Equation (6) is the average radius of sand particles $\overline{r_{s}}$, which can be calculated with sieve analysis results of sand. The number of sand particles in unit volume mortar $N$ is firstly calculated with

$$
N=\sum_{i=1}^{M-1} \frac{W C_{i}}{\frac{4}{3} \pi\left(\left(d_{i}+d_{i+1}\right) / 2\right)^{3} \rho}
$$

where $W$ is the mass of sand in unit volume mortar $(\mathrm{kg})$ and $\rho$ is the density of sand $\left(\mathrm{kg} / \mathrm{m}^{3}\right), C_{i}$ is the mass fraction of sand with diameter between $d_{i}$ (mesh size of the $i^{\text {th }}$ sieve) and $d_{i+1}$ and $M$ is the number of sieves. The average radius of sand particles can then be obtained with

$$
\overline{r_{s}}=\left(\frac{3 W / \rho}{4 \pi N}\right)^{1 / 3}
$$

With known $t_{i}$ (thickness of ITZ) and $\overline{r_{s}}$ (average radius of sand), $\bar{\varepsilon}$ can be easily determined, and the permeability of ECC matrix can then be calculated with Equation (6).

The influences of PVA fiber on permeability are complicated and not fully understood yet. Basically, fibers can be regarded as a special aggregate and have similar effects with aggregates on transport property of cement-based materials. On the other hand, fiber can effectively inhibit the initiation and propagation of microcracks in the matrix, which 
could result in lower permeability. Overall, the addition of PVA fiber slightly reduces the permeability of mortar, and its influence can be expressed with

$$
\kappa_{E C C}=\kappa_{m}\left(1-V_{f}\right)
$$

where $V_{f}$ is the volume fraction of PVA fiber.

\section{Experimental Program}

\subsection{Materials and Mix Proportions}

Mixture proportions of the tested ECC and its matrix mortar are given in Table 1. The proportions for ECC were adopted from preliminary work [9]. The volume fraction of polyvinyl alcohol (PVA) fibers for ECC was $2 \%$, which was a typical dosage of fiber for preparing ECC to satisfy the condition of pseudo strain-hardening and exhibiting high strain capacity after first cracking [2]. The PVA fibers were purchased from KuraRay Company, Japan. According to the supplier, the PVA fibers had a density of $13 \mathrm{~kg} / \mathrm{m}^{3}$, with a length of $8 \mathrm{~mm}$ and a diameter of $40 \mu \mathrm{m}$. The tensile strength of PVA fibers was $1560 \mathrm{MPa}$, and the elastic modulus was $40 \mathrm{GPa}$. Natural sand with a maximum grain size of $1.19 \mathrm{~mm}$ and a density of $2650 \mathrm{~kg} / \mathrm{m}^{3}$ was used as fine aggregate. The sieve analysis results of sand are shown in Table 2.

Table 1. Mixture proportions of ECC and $\operatorname{mortar}\left(\mathrm{kg} / \mathrm{m}^{3}\right)$.

\begin{tabular}{ccc}
\hline Ingredient & ECC & Mortar \\
\hline Cement, ASTM Type I & 385 & 385 \\
Fly ash, Class C & 770 & 770 \\
Silica fume & 77 & 77 \\
Natural sand, maximum size of 1.19 & 462 & 462 \\
mm & 333 & 333 \\
Water & 2 & 1.7 \\
Superplasticizer & 26 & 0 \\
PVA fiber & & \\
\hline
\end{tabular}

Table 2. Sieve analysis result of sand.

\begin{tabular}{ccccc}
\hline Mesh Size $(\mathrm{mm})$ & 1.18 & 0.6 & 0.3 & 0.15 \\
\hline Percentage of sieve residue $(\%)$ & - & 43.73 & 48.18 & 7.89 \\
\hline
\end{tabular}

Three specimens were tested for uniaxial tensile performance. The shape and size of the specimens were shown in Figure 2. A closed-loop controlled Instron testing system (Instron, Norwood, MA, USA) was used in displacement-controlled mode to conduct the tensile test at a loading rate of $0.002 \mathrm{~mm} / \mathrm{s}$. ECC specimens in this study exhibited an elastoplastic behavior with minor strain-hardening and a tensile strength of $4.43 \mathrm{MPa}$ at 28 days, while the mortar specimens depicted a brittle response with a low tensile strength of about 1.83 MPa. After the first cracking in ECC, the load continued to increase concurrently with multiple cracking, which contributed to the inelastic strain capacity as high as $3.89 \%$. The crack opening measured after unloading was between $40-80 \mu \mathrm{m}$, and the crack spacing was about $2 \mathrm{~mm}$. 


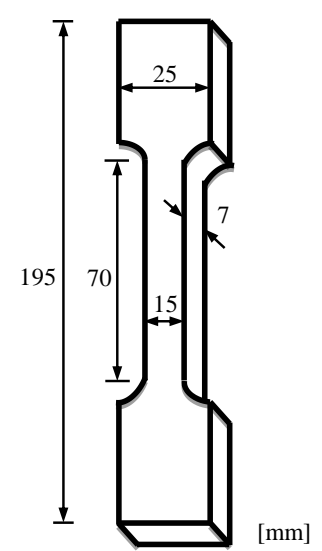

Figure 2. Illustration of specimen for uniaxial tensile test.

\subsection{Water Permeability Test Method}

The water permeability test setups were adapted from Bhargava and Banthia [39], which were originally developed at University of British Columbia, Vancouver, Cananda. Cylindrical specimens (102 $\mathrm{mm}$ in diameter and $204 \mathrm{~mm}$ long) were cast with a hollow cylindrical core which was $73 \mathrm{~mm}$ in diameter. A schematic representation of the apparatus designed for carrying out water permeability tests is shown in Figure 3. The water permeability coefficients of specimens at three different ages $(7 \mathrm{~d}, 28 \mathrm{~d}$ and $90 \mathrm{~d})$ were determined. The specimens were cured in tap water at $20{ }^{\circ} \mathrm{C}$ until $24 \mathrm{~h}$ before the permeability test. After being taken out from water, the specimens were dried in the lab for approximately $8 \mathrm{~h}$ and then glued with O-rings to both ends to avoid water leakage during the permeability test. In order to measure the permeability under a steady state, the specimens needed to achieve a water saturated state before any data were recorded. The preconditioning methods could influence the saturation degree of the specimens [40], and the time needed to achieve steady-state water flow varies consequently. Typically, it took approximately $1 \mathrm{~h}$ after the start of the test to achieve the condition of full flow equilibrium. More details about the preparation work can be found in [39]. After some preliminary tests, a constant inflow water pressure of 50 psi $(0.35 \mathrm{MPa})$ was adopted for permeability tests in this study.

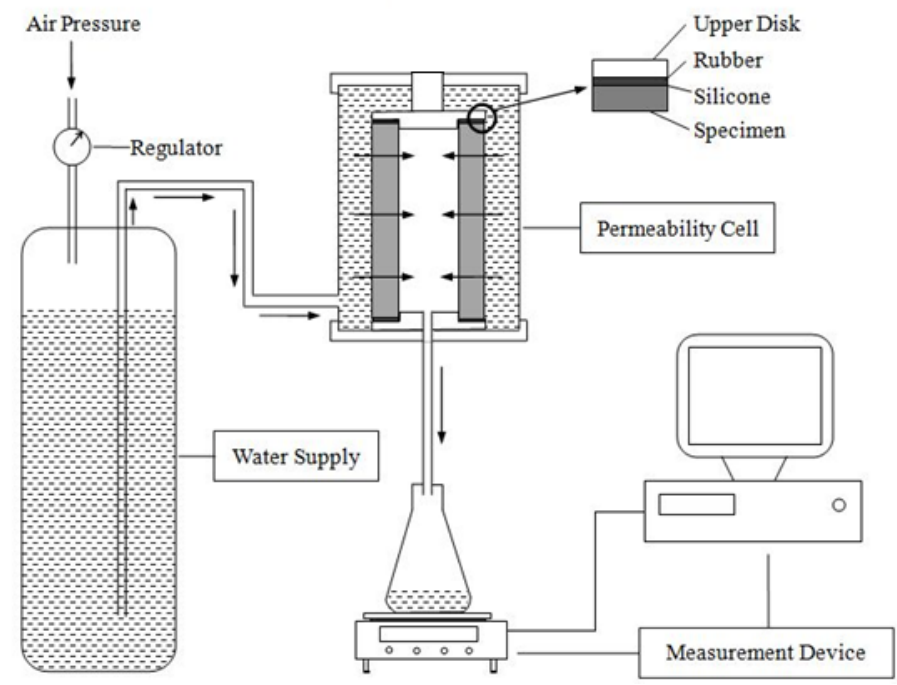

Figure 3. Setup for water permeability test. 
The mass of the water permeated through the cell was collected in collection reservoir and was measured as a function of time. The water permeability coefficient $K_{W}$ was then calculated with an equation [41] derived from Darcy's law:

$$
K_{W}=\frac{Q \cdot \ln \left(r_{2} / r_{1}\right)}{2 \pi h \cdot \Delta H}
$$

where $Q$ equals the rate of water flow $\left(\mathrm{m}^{3} / \mathrm{s}\right) ; r_{1}$ and $r_{2}$ are the inner radius and outer radius of the specimen $(\mathrm{m}) ; h$ equals the height of the specimen $(\mathrm{m}) ;$ and $\Delta H$ is the difference in hydraulic head between the inner and the outer sides of the specimen $(\mathrm{m})$. Three specimens were tested to get an averaged water permeability coefficient.

\section{Results and Discussion}

\subsection{Calculation of $\kappa_{p}$}

The microstructures of ECC paste at three different ages $(7 \mathrm{~d}, 28 \mathrm{~d}$ and $90 \mathrm{~d})$ were simulated with the HYMOSTRUC model, the information needed for determining $\kappa_{h}, \kappa_{l}$ and the calculated permeability of paste are shown in Table 3. As the volume of C-S-H gel increases with curing age, the porosity and pore size of the paste decreases, resulting in a much lower permeability.

Table 3. Calculated permeability of ECC paste.

\begin{tabular}{ccccc}
\hline Age $(\mathrm{d})$ & $\boldsymbol{\varphi}_{\boldsymbol{p}} \mathbf{( \% )}$ & $\boldsymbol{r}_{\text {peak }}(\mathbf{n m})$ & $\boldsymbol{V}_{C-\mathrm{S}-\boldsymbol{H}}(\mathbf{\%})$ & $\boldsymbol{\kappa}_{\boldsymbol{p}}\left(\mathbf{m}^{\mathbf{2}}\right)$ \\
\hline 7 & 28.7 & 140 & 31.2 & $1.80 \times 10^{-18}$ \\
28 & 21.1 & 77 & 40.7 & $4.85 \times 10^{-20}$ \\
90 & 15.8 & 42 & 61.0 & $7.83 \times 10^{-22}$ \\
\hline
\end{tabular}

\subsection{Calculation of $\kappa_{E C C}$}

The permeability of the ECC matrix $\kappa_{m}$ was calculated with a general self-consistent scheme. The volume fraction of sand $V_{s}=17.57 \%$ was determined based on the mixture proportions. According to Equation (6), the parameter to be determined to calculate $\kappa_{m}$ was $\bar{\varepsilon}$, which was the ratio of the thickness of ITZ $t_{i}(20 \mu \mathrm{m})$ to the average radius of sand particles $\overline{r_{S}} \cdot \overline{r_{S}}$ was calculated with Equations (9) and (10) using sieve analysis result of sand shown in Table 2 and the result of $\overline{r_{S}}=0.43 \mathrm{~mm}$ was obtained.

The permeability of ITZ $\kappa_{i}$ was calculated with Equation (8). Substituting the results of $\kappa_{p}, \kappa_{i}$ and $\bar{\varepsilon}$ into Equation (6), the permeability of ECC matrix $\kappa_{m}$ can be determined, and then used to calculate the permeability of ECC $\kappa_{E C C}$ with Equation (11). The calculated results of $\kappa_{E C C}$ at three different ages are shown in Table 4.

Table 4. Calculated permeability of ECC.

\begin{tabular}{ccccccc}
\hline Age (d) & $\varphi_{i} / \varphi_{p}$ & $\varphi_{i}(\%)$ & $r_{i}(\mathbf{n m})$ & $\kappa_{i}\left(\mathbf{m}^{2}\right)$ & $\kappa_{m}\left(\mathbf{m}^{2}\right)$ & $\kappa_{E C C}\left(\mathbf{m}^{2}\right)$ \\
\hline 7 & 1.53 & 43.8 & 214 & $2.44 \times 10^{-16}$ & $2.68 \times 10^{-18}$ & $2.63 \times 10^{-18}$ \\
28 & 1.61 & 33.8 & 123 & $8.15 \times 10^{-17}$ & $7.88 \times 10^{-20}$ & $7.72 \times 10^{-20}$ \\
90 & 1.76 & 27.9 & 74 & $2.91 \times 10^{-17}$ & $1.28 \times 10^{-21}$ & $1.26 \times 10^{-21}$ \\
\hline
\end{tabular}

\subsection{Results of Water Permeability Tests}

With determined permeability, the water permeability coefficient of ECC can be calculated with Equation (2). Water permeability tests of ECC and its matrix mortar were performed to verify the accuracy of the calculated permeability and the results are shown in Table 5. The experimental results showed that the water permeability coefficients of both the matrix mortar and ECC decreased over time, especially at an early age. This was because permeability was highly sensitive to the microstructure of the material [42]. Factors that influence the microstructure would show certain impact on the measured permeability $[43,44]$. In this study, it was mostly the continuous hydration of the matrix 
that caused the decrease of permeability over time. Besides, the water permeability of ECC was slightly lower than the matrix mortar, but the difference was negligible. This was in accordance with the results from earlier study [45].

Table 5. Water permeability coefficients of ECC and its matrix mortar.

\begin{tabular}{ccccccc}
\hline \multirow{2}{*}{ Age (d) } & \multicolumn{5}{c}{ Matrix } & \multicolumn{3}{c}{ ECC } \\
\cline { 2 - 7 } & $\boldsymbol{K}_{\boldsymbol{m}}(\mathbf{m} / \mathbf{s})$ & $\boldsymbol{K}_{m}^{\text {test }}(\mathbf{m} / \mathbf{s})^{1}$ & Deviation $\mathbf{( \% )}^{\text {test }}(\mathbf{m} / \mathbf{s})^{2}$ & $\boldsymbol{K}_{E C C}(\mathbf{m} / \mathbf{s})$ & $\boldsymbol{K}_{\text {ECC }}$ & Deviation $(\mathbf{\%})$ \\
\hline 7 & $2.62 \times 10^{-11}$ & $2.15 \times 10^{-11}$ & 21.9 & $2.57 \times 10^{-11}$ & $2.03 \times 10^{-11}$ & 26.6 \\
28 & $7.72 \times 10^{-13}$ & $8.78 \times 10^{-13}$ & 12.7 & $7.56 \times 10^{-13}$ & $8.39 \times 10^{-13}$ & 9.8 \\
90 & $1.26 \times 10^{-14}$ & $1.72 \times 10^{-14}$ & 27.1 & $1.23 \times 10^{-14}$ & $1.48 \times 10^{-14}$ & 16.9 \\
\hline
\end{tabular}

${ }^{1} K_{m}^{\text {test }}$ is the measured water permeability coefficient of matrix mortar. ${ }^{2} K_{E C C}^{\text {test }}$ is the measured water permeability coefficient of ECC.

The deviation between the calculated and measured water permeability coefficients are up to $27.1 \%$. It is generally agreed that a deviation of up to $30 \%$ is acceptable for cementitious materials [46]. Therefore, the proposed model for permeability of ECC is basically reliable.

The influences of fibers on permeability of concrete are complicated. It depends on the fiber types, fiber content, constituents of concrete matrix and their resulting microstructure, and more importantly, service conditions of the concrete. It is generally agreed that fibers would greatly improve the permeability of loaded concrete due to their superior ability of inhibiting cracking. For unloaded specimens, the ITZ between fibers and cement paste could accelerate the water transport, and the effect depends on the microstructure of the matrix. On the other hand, fiber can effectively inhibit the initiation and propagation of microcracks in the matrix, which could result in lower permeability. Moreover, the presence of fibers reduces the volume fraction of cement paste, which results in lower permeability as well. The apparent influence of fiber on permeability is the integrated results of the factors mentioned above. Overall, based on the results from the literature [5,47], fiber reinforced concrete has similar or slightly lower permeability compared with plain concrete for unloaded specimens. Therefore, the effect of fibers on permeability was simplified with a parameter of $\left(1-V_{f}\right)$. The influences of fibers on permeability of concrete need further study and the proposed model will be improved in future work.

\section{Conclusions}

A simple model for the prediction of permeability of ECC was proposed and discussed in this paper. The microstructure of ECC paste was simulated with the HYMOSTRUC model, and then used to determine the permeability of ECC paste with GEM theory. The permeability of the ECC matrix was then calculated with the GSCS method. The porosity and permeability of ITZ were first determined, and other parameters in the scheme were calculated based on the information of mix proportions. The permeability of ECC was calculated and the influence of PVA fibers was considered with its volume fraction.

Water permeability tests were performed to verify the reliability of the proposed model. The test results demonstrated that the addition of PVA fibers could slightly decrease the water permeability coefficient of ECC. The deviation between the calculated and measured water permeability coefficients was up to $27.1 \%$, which is reasonable for cement-based materials. Overall, the proposed model can be used for predicting permeability of ECC and provide reliable results.

Author Contributions: Conceptualization, Q.W.; Methodology, Q.W. and G.Z.; Software, C.G.; Validation, Y.T.; Writing-Original draft, Q.W. and G.Z.; Writing-Review and editing, G.Z. and Y.T. All authors have read and agreed to the published version of the manuscript.

Funding: This research was funded by the National Natural Science Foundation of China, grant number 52008372 and 51708502.

Institutional Review Board Statement: Not applicable. 
Informed Consent Statement: Not applicable.

Data Availability Statement: Data is contained within the article.

Conflicts of Interest: The authors declare no conflict of interest.

\section{References}

1. Liu, T.; Zhang, P.; Li, Q.; Hu, S.; Ling, Y. Durability Assessment of PVA Fiber-Reinforced Cementitious Composite Containing Nano-SiO2 Using Adaptive Neuro-Fuzzy Inference System. Crystals 2020, 10, 347. [CrossRef]

2. Li, V.C. From micromechanics to structural engineering-the design of cementitious composites for Civil engineering applications. Proc. Jpn. Soc. Civ. Eng. 1993, 471, 37-48. [CrossRef]

3. Li, V.C.; Leung, C.K.Y. Steady-state and multiple cracking of short random fiber composites. J. Eng. Mech. 1992, 118, 2246-2264. [CrossRef]

4. Wang, Q.; Banthia, N.; Sun, W. Water permeability of repair mortars under an applied compressive stress at early ages. Mater. Struct. 2018, 51, 6. [CrossRef]

5. Lepech, M.D.; Li, V.C. Water permeability of engineered cementitious composites. Cem. Concr. Comp. 2009, 31, 744-753. [CrossRef]

6. Liu, H.; Zhang, Q.; Gu, C.; Su, H.; Li, V.C. Influence of microcrack self-healing behavior on the permeability of Engineered Cementitious Composites. Cem. Concr. Comp. 2017, 82, 14-22. [CrossRef]

7. Liu, H.; Zhang, Q.; Gu, C.; Su, H.; Li, V.C. Influence of micro-cracking on the permeability of engineered cementitious composites. Cem. Concr. Comp. 2016, 72, 104-113. [CrossRef]

8. Wagner, C.; Villmann, B.; Slowik, V.; Mechtcherine, V. Water permeability of cracked strain-hardening cement-based composites. Cem. Concr. Comp. 2017, 82, 234-241. [CrossRef]

9. Wang, Q.; Banthia, N. Water permeability of Eco-Friendly Ductile Cementitious Composites (EDCC) under an applied compressive stress. Cem. Concr. Comp. 2020, 107, 103500. [CrossRef]

10. Zhang, M.; He, Y.; Ye, G.; Lange, D.A.; Breugel, K.V. Computational investigation on mass diffusivity in Portland cement paste based on X-ray computed microtomography $(\mu \mathrm{CT})$ image. Constr. Build. Mater. 2012, 27, 472-481. [CrossRef]

11. Christensen, B.J.; Mason, T.O.; Jennings, H.M. Comparison of measured and calculated permeabilities for hardened cement pastes. Cem. Concr. Res. 1996, 26, 1325-1334. [CrossRef]

12. El-Dieb, A.S.; Hooton, R.D. Evaluation of the Katz-Thompson model for estimating the water permeability of cement-based materials from mercury intrusion porosimetry data. Cem. Concr. Res. 1994, 24, 443-455. [CrossRef]

13. Koster, M.; Hannawald, J.; Brameshuber, W. Simulation of water permeability and water vapor diffusion through hardened cement paste. Comput. Mech. 2006, 37, 163-172. [CrossRef]

14. Park, S.S.; Kwon, S.J.; Jung, S.H.; Sang, W.L. Modeling of water permeability in early aged concrete with cracks based on micro pore structure. Constr. Build. Mater. 2012, 27, 597-604. [CrossRef]

15. Cui, L.; Cahyadi, J.H. Permeability and pore structure of OPC paste. Cem. Concr. Res. 2001, 31, 277-282. [CrossRef]

16. Zhang, M. Multiscale Lattice Boltzmann-Finite Element Modelling of Transport Properties in Cement-Based Materials. Doctoral Thesis, Delft University of Technology, Delft, The Netherlands, 2013.

17. Li, L.; Xia, J.; Lin, S. A multi-phase model for predicting the effective diffusion coefficient of chlorides in concrete. Constr. Build. Mater. 2012, 26, 295-301. [CrossRef]

18. Hashin, Z. Thin interphase/imperfect interface in conduction. J. Appl. Phys. 2001, 89, 2261-2267. [CrossRef]

19. Garboczi, E.J.; Bentz, D.P. Multiscale Analytical/Numerical Theory of the Diffusivity of Concrete. Adv. Cem. Based Mater. 1998, 8 , 77-88. [CrossRef]

20. Oh, B.H.; Jang, S.Y. Prediction of diffusivity of concrete based on simple analytic equations. Cem. Concr. Res. 2004, 34, 463-480. [CrossRef]

21. Marchand, J.; Gerard, B. Microstructure-based models for predicting transport properties. In Penetration and Permeability of Concrete: Barriers to Organic and Contaminating Liquids; Reinhardt, H.W., Ed.; E \& FN Spon: London, UK, 1997 ; pp. 41-81.

22. $\mathrm{Hu}, \mathrm{J} . ;$ Stroeven, P. Application of image analysis to assessing critical pore size for permeability prediction of cement paste. Image Anal. Stereol. 2003, 22, 97-103. [CrossRef]

23. Powers, T.C. Structure and Physical Properties of Hardened Portland Cement Paste. J. Am. Ceram. Soc. 1958, 41, 1-6. [CrossRef]

24. Bentz, D.P.; Garboczi, E.J.; Martys, N.S. Application of digital-image-based models to microstructure, transport properties, and degradation of cement-based materials. In The Modelling of Microstructure and Its Potential for Studying Transport Properties and Durability; Jennings, H., Kropp, J., Scrivener, K., Eds.; Springer: Dordrecht, The Netherlands, 1996; pp. 167-185. [CrossRef]

25. Zhang, M. Pore-scale modelling of relative permeability of cementitious materials using X-ray computed microtomography images. Cem. Concr. Res. 2017, 95, 18-29. [CrossRef]

26. Sun, M.; Zhu, J.; Li, N.; Fu, C. Experimental Research and Finite Element Analysis on Mechanical Property of SFRC T-Beam. Adv. Civ. Eng. 2017, 2017, 2721356. [CrossRef]

27. Van Breugel, K. Simulation of Hydration and Formation of Structure in Hardening Cement-Based Materials. Doctoral Thesis, Delft University of Technology, Delft, The Netherlands, 1997.

28. Bentz, D.P. Three-Dimensional Computer Simulation of Portland Cement Hydration and Microstructure Development. J. Am. Ceram. Soc. 1997, 80, 3-21. [CrossRef] 
29. Bishnoi, S.; Scrivener, K.L. $\mu$ ic: A new platform for modelling the hydration of cements. Cem. Concr. Res. 2009, 39, 266-274. [CrossRef]

30. Maekawa, K.; Chaube, R.; Kishi, T. Modelling of Concrete Performance: Hydration, Microstructure and Mass Transport; E \& FN Spon: London, UK, 2014.

31. Ye, G.; Van Breugel, K.; Fraaij, A. Three-dimensional microstructure analysis of numerically simulated cementitious materials Cem. Concr. Res. 2003, 33, 215-222. [CrossRef]

32. Gu, C. Chloride Transport Property and Service Life Prediction of UHPFRCC under Flexural Load. Doctoral Thesis, Southeast University, Nanjing, China, 2016. (In Chinese)

33. Zhang, M.; Ye, G.; Van Breugel, K. Microstructure-based modeling of water diffusivity in cement paste. Constr. Build. Mater. 2011, 25, 2046-2052. [CrossRef]

34. Andrade, C. Calculation of chloride diffusion coefficients in concrete from ionic migration measurements. Cem. Concr. Res. 1993, 23, 724-742. [CrossRef]

35. Zheng, J.; Li, C.; Zhou, X. Characterization of microstructure of interfacial transition zone in concrete. ACI Mater. J. 2005, 102, 265-271.

36. Sun, G. Transport Behaviors and Multi-Scale Modeling of Chloride Ions in Cement-Based Composite Materials. Doctoral Thesis, Southeast University, Nanjing, China, 2014. (In Chinese)

37. Katz, A.J.; Thompson, A.H. Quantitative Prediction of Permeability and Electrical-Conductivity in Porous Rock. Geophysics 1987, 52, 378.

38. Scrivener, K.L.; Crumbie, A.K.; Laugesen, P. The interfacial transition zone (ITZ) between cement paste and aggregate in concrete. Interface. Sci. 2004, 12, 411-421. [CrossRef]

39. Bhargava, A.; Banthia, N. Measurement of concrete permeability under stress. Exp. Tech. 2006, 30, 28-31. [CrossRef]

40. Sanjuán, M.A.; Muñoz-Martialay, R. Oven-drying as a preconditioning method for air permeability test on concrete. Mater. Lett. 1996, 27, 263-268. [CrossRef]

41. Fang, Y.; Wang, Z.; Zhou, Y. Time-dependent water permeation behavior of concrete under constant hydraulic pressure. Water Sci. Eng. 2008, 1, 61-66. [CrossRef]

42. Argiz, C.; Sanjuán, M.A.; Muñoz-Martialay, R. Effect of the aggregate grading on the concrete air permeability. Mater. Constr. 2014, 64, 315. [CrossRef]

43. Sanjuan, M.A.; Muñoz-Martialay, R. Influence of the water/cement ratio on the air permeability of concrete. J. Mater. Sci. 1996, 31, 2829-2832. [CrossRef]

44. Sanjuán, M.A.; Muñoz-Martialay, R. Variability of the concrete air permeability coefficient with time. Build. Environ. 1997, 32, 51-55. [CrossRef]

45. Roque, R.; Kim, N.; Kim, B.; George, L. Durability of Fiber-Reinforced Concrete in Florida Environments; University of Florida: Gainesville, FL, USA, 2009.

46. Sun, G.; Sun, W.; Zhang, Y.; Liu, Z. Multi-scale Modeling of the Effective Chloride Ion Diffusion Coefficient in Cement-based Composite Materials. J. Wuhan Univ. Technol. Mater. Sci. Ed. 2012, 27, 364-373. [CrossRef]

47. Gu, C.; Ye, G.; Sun, W. A review of the chloride transport properties of cracked concrete: Experiments and simulations. J. Zhejiang Univ. Sci. A 2015, 16, 81-92. [CrossRef] 